\title{
Incidence and Prevalence of Multiple Sclerosis in Newfoundland and Labrador
}

\author{
J.S. Sloka, W.E.M. Pryse-Phillips, M. Stefanelli
}

\begin{abstract}
Background: The incidence and prevalence of multiple sclerosis (MS) in Newfoundland and Labrador (NL) had been reported in 1984 and was considered to be relatively low at that time. This study revisits the incidence and prevalence of MS in NL for the year 2001. Methods: Case searches through patient files of neurologists in NL were conducted. A complete list of patients billed for MS in NL between 1996 and 2003 was obtained and all cases were confirmed via chart review. Results: There were 493 living MS patients yielding a prevalence of 94.4/100,000 which is significantly higher than previously reported. Of the living patients, 330 had relapsing remitting (RRMS), 94 had secondary progressive, 66 had primary progressive (PPMS) and three had unspecified MS. The total female to male ratio was 2.7:1. There was no difference between the female to male ratios for RRMS vs PPMS. Patients with PPMS had a later onset compared to RRMS ( $\mathrm{p}<0.00001)$. Yearly incidences were relatively constant from 1994 to 2001 (5.6/100,000). Significant delays between first symptoms and final diagnosis were common and the delay time has not changed over the past 15 years. A prevalence of 88.9/100,000 was estimated from survival and incidence trends and was not significantly different than the measured prevalence $(\mathrm{p}=0.38)$. Conclusions: The increase in incidence and prevalence are accounted for through both better access to diagnostic facilities and more practicing neurologists. The revised prevalence and incidence are more in keeping with recently reported values throughout Canada.
\end{abstract}

RÉSUMÉ: Incidence et prévalence de la sclérose en plaques à Terre-Neuve et au Labrador. Introduction: L'incidence et la prévalence de la sclérose en plaques (SEP) à Terre-Neuve et au Labrador (TNL) ont été rapportées en 1984 et elles étaient considérées comme basse à cette époque. Cette étude révise l'incidence et la prévalence de la SEP à TNLen 2001. Méthodes: Nous avons procédé à une recherche de cas dans les dossiers de neurologues de TNL. Une liste complète de patients dont la note d'honoraires mentionnait le diagnostic de SEP à TNL entre 1996 et 2003 a été compilée et tous les cas ont été confirmés par une revue de dossiers. Résultats: Il y avait 493 patients vivants atteints de SEP, soit une prévalence de 94,4/100,000 habitants, un chiffre nettement plus élevé que celui rapporté antérieurement. Parmi les patients vivants, 330 avaient la forme cyclique (SEPC), 94 la forme progressive secondaire (SEPPS), 66 la forme progressive primaire (SEPPP) et trois avaient une forme indéterminée. Le rapport femmes/hommes était de 2,7/1 et il n'y avait pas de différence entre le rapport femmes/hommes pour la SEPC et la SEPPP. Les patients atteints de SEPPP avaient un début plus tardif que ceux atteints de SEPC ( $<00,00001)$. L'incidence annuelle était relativement constante de 1994 à 2001 (5,6/100,000). Un délai important entre les premiers symptômes et le diagnostic final était fréquent et la longueur de ce délai n'a pas changé au cours des 15 dernières années. Une prévalence de 88,9/100,000 a été estimée à partir des tendances de survie et d'incidence et n'était pas significativement différente de la prévalence mesurée $(\mathrm{p}=0,38)$. Conclusions: L'augmentation de l'incidence et de la prévalence se justifient par une plus grande accessibilité aux moyens diagnostiques et par la présence d'un plus grand nombre de neurologues. La prévalence et l'incidence que nous rapportons sont plus conformes à celles rapportées récemment à travers le Canada.

Can. J. Neurol. Sci. 2005; 32: 37-42

Multiple sclerosis (MS) is a chronic disease of the central nervous system. It damages oligodendroglia and axons and may cause paralysis, sensory disturbances, incoordination, visual impairment, and alterations in bowel, bladder, and sexual function. ${ }^{1}$ The precise etiology of MS has not been elucidated; however, many observations suggest that both genetic susceptibility and environmental factors are implicated. ${ }^{2}$
From the Faculty of Medicine (Neurology), Memorial University of Newfoundland, (JSS); Faculty of Medicine (Neurology), Health Sciences Center (WEMP-P, MS); St. John's, NL, Canada

ReCeived May 31, 2004. ACCEPTEDinfinalform OCtOBER 7, 2004. Reprint requests to: J. Scott Sloka, Faculty of Medicine (Neurology), Memorial University of Newfoundland, 108 Moss Heather Dr., St. John's, NL, Canada A1B 4S1. E-mail: p97jss@mun.ca 
Epidemiological data have contributed greatly to the study of $\mathrm{MS}^{3}$ and continue to play a major role in the search for etiology. ${ }^{4,5}$ Genetically isolated populations have contributed significantly in the search for susceptibility genes for monogenetic disorders such as MEN1, ${ }^{6}$ hemophilia $\mathrm{A}^{7}$ and APC ${ }^{8}$ At present, there is renewed interest in these populations ${ }^{9}$ to identify susceptibility genes ${ }^{10,11}$ and environmental contributions $^{4,5}$ for complex diseases such as MS.

Newfoundland and Labrador (NL) is Canada's easternmost province and its population is a rare circumstance in the investigation of complex disease ${ }^{12}$ due to the history of its settlement, its subsequent founder effect, and its geographical isolation. ${ }^{13}$ Newfoundland, the island portion, lies between latitudes 46 and 52N and longitudes 52 and 59W. The mainland section, Labrador, is situated between 52 and $61 \mathrm{~N}$ and 56 and $67 \mathrm{~W}$. Newfoundland and Labrador has an area of $405,720 \mathrm{~km}^{2}$, a population of 521,986 (49\% urban) ${ }^{14}$ settled mostly along the sea coast. Approximately $60 \%$ of the inhabitants live in settlements with populations less than 2500. ${ }^{14}$ It was rediscovered by Europeans in 1497, colonies were established by 1610 , and the population grew from 20,000 settlers in 1760 to 200,000 in 1890 by natural expansion, ${ }^{12}$ representing a strong founder effect. Approximately $98 \%$ of the population is of English or Irish descent. ${ }^{14}$ After initial settlement, both inmigration and regional migration within the province remained low and subsequently, persistent genetic isolation has been confirmed in selected settlements. ${ }^{15-17}$ Significant outmigration has occurred only recently in selected Newfoundland settlements (in the order of $10 \%){ }^{14}$

An epidemiological study was undertaken prior to 1984 to determine the previously unreported incidence and prevalence of MS in NL and to establish an MS registry to follow future incidence trends. ${ }^{18}$ In order to update the previous study and to re-establish the MS registry for the further investigation of etiology (both genetic and environmental), an updated incidence and prevalence study of MS in NLwas undertaken. Since certain geographical regions have reported an increase in MS prevalence secondary to increases in reported incidences, ${ }^{19-21}$ a similar trend was also suspected in NL and this was investigated.

\section{Methods}

The Canadian province of NL comprises the island of Newfoundland and the mainland part of Labrador. Presently, nine practicing neurologists receive roughly 15,300 patient visits yearly covering all illnesses for a population of 521,986 (year 2001). Additionally, two authors (WP-P and MS) have, in turn, conducted a weekly clinic dedicated specifically to MS patients. All physician billing for the province is coordinated through the Medical Care Plan (MCP) provincial health insurance system. There is one tertiary care center on the island with one MRI device, first installed in 1993.

Case finding of MS patients was conducted by hand searching for patients with a diagnosis of MS through all the patient records of most (8/9) of the practicing neurologists in the province, although all neurologists have been referring patients' names with new MS diagnoses to the MS clinic for several years. Search accuracy was greatly enhanced by the provision by MCP of billing records based upon the ICD- 9 code 340 for the fiscal years April 1, 1996 to March 31, 2003. The release of records was made possible through an official government Order in Council to MCP in conjunction with ethical approval of our Human Investigation Committee. Three previous databases (one from the previous 1984 study, one from a localized study in Gander, NL, and one kept in Vancouver for genetic research) were combined to determine both current and historical diagnoses.

Once an initial list was generated (approximately 1,200 records), both neurologist and hospital patient records were reviewed to confirm the diagnosis of clinically definite MS. Given the historical progression of the definition of clinically probable and definite $\mathrm{MS},{ }^{22-24}$ records were reviewed and only those patients that met the Poser criteria were included. All confirmed diagnoses demonstrated clinical evidence of two attacks separated by time and space (usually supported by clinical laboratory evidence) as judged by the attending neurologist, and were consistent with the Poser committee criteria. ${ }^{23}$ Information on gender, date of birth, age at first attack, age at diagnosis, and type of MS was consistently captured from the records.

Categorization of the type of MS was based on the findings of an international survey of MS experts. ${ }^{25}$ Patients were clinically classified as having relapsing-remitting (RRMS), secondary progressive (SPMS), and primary progressive (PPMS) disease. ${ }^{25}$ Any patients with previously diagnosed progressive remitting were recategorized as PPMS once their charts were appropriately reviewed, ${ }^{26}$ and any patients with previously categorized remitting progressive were recategorized into the PPMS or SPMS $^{27}$ groups as per their initial course. ${ }^{26}$ There were no patients specifically categorized as malignant MS, and the few patients that have the clinical diagnosis of benign MS are categorized as RRMS.

Once the list of diagnosed patients was confirmed, a search (keyed to patient name, date of birth and an unique MCP identifier) for death notices of these patients was conducted through the Newfoundland and Labrador Center for Health Information. This generated a list of patients with MS in NLwho were alive on December 31, 2001, yielding a confirmed prevalence of clinically definite MS at that date.

Ninety-five per cent confidence intervals were calculated assuming a Poisson distribution. Crude rates were applied to both current ${ }^{14}$ and historical census information. Student's t test

\section{Table 1: Demographics of initial case finding for 491 confirmed cases of MS, alive on Dec 31, 2001}

\begin{tabular}{lcccc}
\hline Type of MS & Female & Male & Ratio $(\mathbf{F : M})$ & Total \\
RRMS & 248 & 82 & $3.02: 1$ & 330 \\
SPMS & 67 & 27 & $2.48: 1$ & 94 \\
PPMS & 42 & 24 & $1.75: 1$ & 66 \\
Other & 2 & 1 & $2.00: 1$ & 3 \\
Total & 359 & 134 & $2.68: 1$ & 493 \\
\hline
\end{tabular}

RRMS - relapsing remitting MS, SPMS - secondary progressive MS, PPMS - primary progressive MS, Other - includes unspecified MS, benign MS, relapsing progressive MS, progressive relapsing MS. 


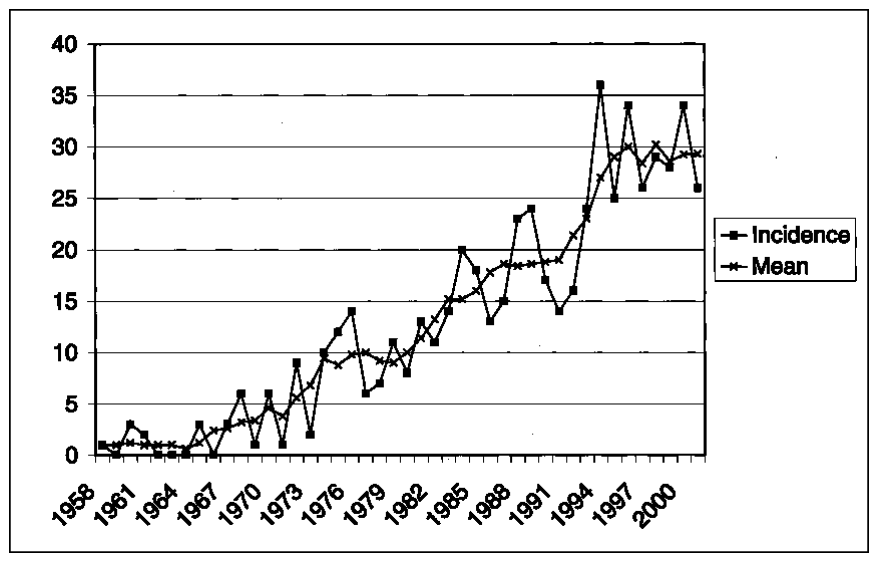

Figure 1: The crude incidence of diagnosis and five-point running mean (average of current year, previous two years and following two years) for 571 patients identified with MS in NL from 1958 to 2001. The first MRI in the province was installed in 1993.

and $\mathrm{Z}$ test were applied to compare averages and rates, respectively. An $\alpha$ of 0.05 was selected for tests of significance.

\section{RESULTS}

Of all patient records that were reviewed, the diagnosis of MS was confirmed in 571 people. Of those, 493 were alive on December 31, 2001, giving a population prevalence of 94.4 per 100,000 (95\% CI: 90.2-98.7). The patient age range was 16-87 years (mean 46.0). Demographics for these patients based on diagnosis type are shown in Table 1 . The female/male ratio was (marginally) significantly different between RRMS and PPMS $(\mathrm{p}=0.054)$.

Incidence was determined both by incidence of first attack (or first clinical appearance in the case of PPMS) and by incidence of diagnosis. Figure 1 shows the raw incidences of diagnosis for

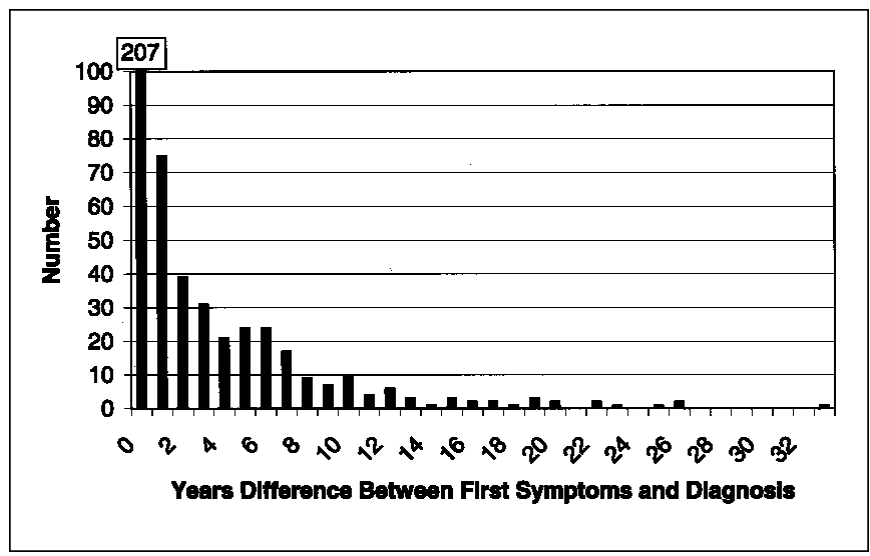

Figure 3: A histogram of the time lag between the onset of symptoms and the final diagnosis.

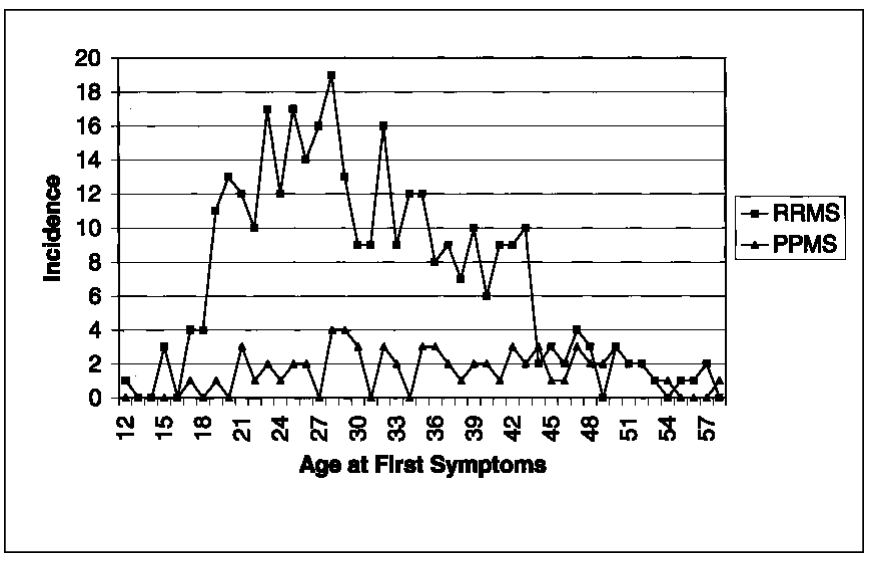

Figure 2: A histogram of the age at first symptoms for both RRMS (average 31.0) and PPMS (average 37.0). Note the tendency for a later age of onset for first symptoms of PPMS over RRMS.

all 571 cases (both alive and deceased). The running mean over the current year, previous two years and following two years is also plotted to demonstrate the general (smoothed) trend. A more lengthy than usual (five year) running mean was chosen because of the previously reported six year cyclical nature of the incidence here in Newfoundland. Of note, the eight years from 1994 to 2001 present a fairly consistent mean incidence of 29.0 cases per year (5.6 per 100,000). As well, 1987 to 1991 also presents a consistent mean of 18.6 (3.6 per 100,000), significantly different from the current mean of $29.0(\mathrm{p}=0.001)$. The current incidence of 5.6 per 100,000 is also significantly different from the previously reported incidence in 1982 of 2.98 per $100,000(\mathrm{p}<0.001)$.

Figure 2 shows the age at first symptoms for patients with RRMS and PPMS separately. The average age of first symptoms for patients with RRMS was 31.0 years (F 30.7, M 31.8), and the

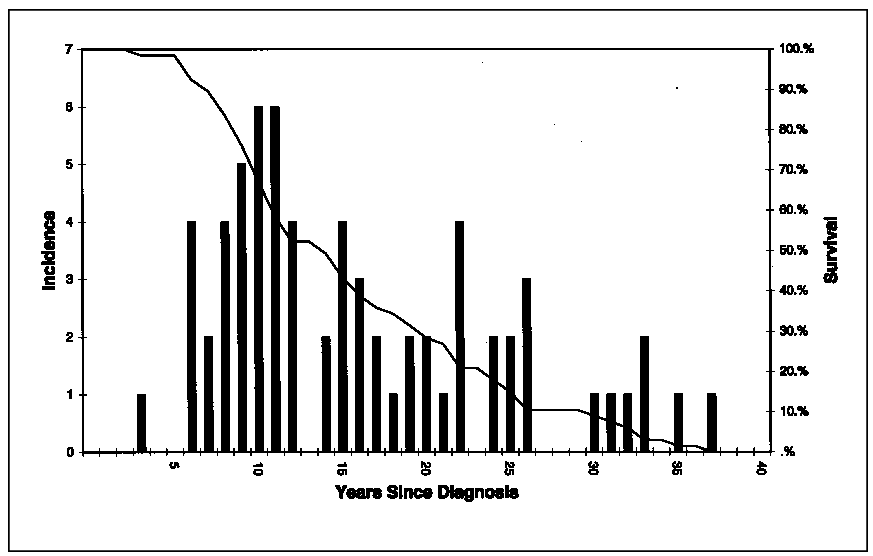

Figure 4: A histogram of the number of years since diagnosis that a patient's expiration is recorded. The survival distribution is represented as a cumulative decrement beginning with $100 \%$ at diagnosis and decrementing according to the number of deaths recorded within each given year. 


\section{Table 2: Prevalence of MS across Canada}

\begin{tabular}{|c|c|c|c|}
\hline Location & Prevalence Date & Prevalence per 100,000 population & SeniorAuthor \\
\hline Winnipeg, Manitoba ${ }^{35}$ & $1939-1948$ & 39.6 & Westlund \\
\hline Winnipeg, Manitoba ${ }^{36}$ & Jan 1,1960 & 35.4 & Stazio \\
\hline British Columbia $^{37}$ & Jul 1, 1982 & 117.2 & Sweeney \\
\hline Saskatoon, Saskatchewan ${ }^{38}$ & Jan 1,1977 & 134 & Hader \\
\hline Newfoundland and Labrador ${ }^{18}$ & Mar 31, 1985 & 55.2 & Pryse-Phillips \\
\hline London, Ontario ${ }^{39}$ & Jan, 1984 & 94 & Hader \\
\hline Crowsnest Pass, Alberta ${ }^{40}$ & $?$ & 217 & Klein \\
\hline Barrhead County, Alberta ${ }^{41}$ & Jan 1,1990 & 196 & Warren \\
\hline Westlock County, Alberta ${ }^{42}$ & Jan 1,1991 & 201 & Warren \\
\hline Alberta $^{43}$ & 1984-1989 & 216.7 & Svenson \\
\hline
\end{tabular}

average age for PPMS was 37.0 years (F 35.9, M 38.8). The tendency for PPMS to have a later onset was significant $(\mathrm{p}<0.00001)$, but the tendency for females to have an earlier onset of symptoms was neither significant for RRMS ( $\mathrm{p}=0.41)$ nor for PPMS ( $\mathrm{p}=0.24)$.

The year of diagnosis was also recorded during the chart review. These data are not plotted here, but the time lag between the self reported first symptoms of MS and the time of diagnosis is plotted in Figure 3. This delay may be due to such factors as access to a neurologist, access to diagnostic equipment (such as the acquisition of the MRI unit in 1993), or original symptoms that went unrecognized either by the patient or the family physician. Fifty-two percent of patients received a diagnosis within the first two years of the initial onset of symptoms. Average delays between first attack to diagnosis for 1996-2001 were 3.6 years versus 3.1 years for 1987-1995, a nonsignificant difference $(\mathrm{p}=0.32)$. This may reflect the continued geographical isolation of the population, the nonrecognition of symptoms as possible first attacks of MS, or restricted access to neurological services.

During the search through expiration records, data on 68 deaths were confirmed. The number of years between the diagnosis of MS until the patient's death is plotted in Figure 4. In the same figure, survival distribution over time is represented as a cumulative decrement beginning with $100 \%$ survival at diagnosis and declining according to the number of deaths recorded within each given year. The expirations peak near 10 years post diagnosis, and the general trend appears to be roughly Poisson distributed. In NL, approximately $50 \%$ of those people diagnosed with MS died from all causes within 15 years of diagnosis. Since the average age of death for MS in NL is 57.8 years (for our reported 68 cases), and the life expectancy in the province is 77.4 years, it would seem that MS patients in NL have a significantly reduced life expectancy.

\section{Discussion}

In NL the prevalence of MS was found to be 94.4 per 100,000 . This is significantly higher than the previously reported value of 55.2 per 100,000 in $1984^{18}(\mathrm{p}<0.0001)$ and may be accounted for by the increased incidence of diagnosis (from approx. 3/100,000 in 1984 to 5.6/100,000 in 2001). We feel that the current estimate of prevalence is extremely accurate - most patients that have attacks or progression (ie. nonbenign MS) visit their physician at least yearly for their MS and this is billed via the province's MCP. This MCP billing information is available for the previous eight years. Chart searches were performed in addition to this billing search to pick up patients who were not billed using the MS code 340, but these chart searches added very little to the known cases derived from MCP records and from previous databases. The current estimate of $94.4 / 100,000$ is well within the range of previously reported prevalences for Canada (Table 2).

The increase in reported prevalence is likely due to the increase in reported incidence. This increased incidence has occurred in conjunction with both the addition of an MRI device in the province and an increase in neurologists practicing outside of the capital city, St John's. The original study noted a relative increase in the prevalence of cases in the region closest to $\mathrm{St}$ John's. This original St John's regional prevalence is similar to the current province-wide prevalence which, on initial review, is more uniform now. Therefore, we feel that this increased prevalence is not likely due to an increase in actual incidence. Rather, we feel that the reporting bias has been reduced due to a more uniform diagnostic coverage.

The reported incidence is subject to several sources of bias. Length time bias becomes more significant the more remote from 2001 that the diagnosis was made. Older incidence figures are available mostly due to a retrospective search through current prevalence and previous databases. Since the 571 patients with confirmed MS were only confirmed through available records and older records may not be as available as newer records (especially if the patient expired several years ago), more recent incidence data will be more accurate. The relatively constant incidence data from 1994 to 2001 may reflect the enhanced accuracy of MCP billing archives that were available for this time period and the fact that some older files may not be available from neurologists' filing systems. However, the difference in incidence between the 1987 to 1991 and 1994 to 2001 time periods may be explained at least partially by the installation of the province's first MRI in 1993, thus facilitating the ability of neurologists to diagnose MS. 
In a prevalence study, case ascertainment bias is an important consideration. The patient charts from one neurologist were not reviewed due to restricted access to his files. However, this neurologist has kindly and continuously been referring a list of all his newly diagnosed and previously diagnosed patients to the MS clinic nurse for the past several years. This case list was used as a source of patients in this study and their hospital charts were reviewed. As well, the case finding through the neurologists' records did not add significantly to the lists of patients provided by MCP and the three previously derived patient lists, providing no more than 10 more names to the complete list of 491 . Therefore, we do not feel that case finding through a thorough search of this neurologist's records would have contributed significantly more, if any, cases to the list, and we do feel that we obtained near complete case ascertainment given the various sources used for case finding. An analytical analysis of the completeness of case ascertainment is described below.

An estimate of prevalence may be calculated using both incidence data and survival distribution. ${ }^{28-32}$ This would be useful to know for future planning of medical services in NL. It would also be useful to compare the calculated prevalence with the measured prevalence to test the internal validity/internal consistency of the measured survival distribution, incidence and prevalence. The prevalence can be calculated by the convolution of the estimate of incidence and the survival distribution and this and related methods have been used in studies for cancer prevalence estimation. ${ }^{33}$ The prevalence is the number of cases in a given population at a given time. ${ }^{28}$ For a population in steady state (constant population, no significant differences in population age makeup or survival traits, etc), it is a summed product of the number of cases previously measured (historic incidence) and the probability that each historic case is alive on the date of measured prevalence. This is simply the sum of all the cases this year times the probability that they will be alive at the end of this year plus all the cases last year times the probability that they will also be alive at the end of this year, etc, or:

$P[n]=I[n] p[0]+I[n-1] p[1]+I[n-2] p[2]+\ldots$

where $\mathrm{P}[\mathrm{n}]$ is the prevalence for the year, $\mathrm{n}$, in which the prevalence is to be estimated, $\mathrm{p}[\mathrm{k}]$ is the survival proportion at year $\mathrm{k}$ (as per Figure 4), and I[k] is the incidence at year $\mathrm{k}$ from the initiating event (in this case, diagnosis). This is, in essence, a discrete time convolution function:

$$
P[n]=\sum_{k=0}^{N} p[k] I[n-k]
$$

In our very simplified estimation, I[k] is a constant 29 new cases per year, and the sum over $\mathrm{p}[\mathrm{k}]$ from year 0 to 36 (the greatest lag between diagnosis and expiration) is $1603 \%$. Therefore, our calculated prevalence given current incidence and current survival distribution is $29 * 16.03$, or 464 (88.9 per $100,000)$. This estimate is valid only for a constant incidence of 29 ad infinitum (which has actually only been true for eight years). As well, this estimate is based on a steady state population distribution that is not the reality for NL.

This estimate of 464 patients is less than the 493 patients that was determined by the current study $(\mathrm{p}=0.36)$, and this nonsignificant difference suggests that this study is internally consistent. The difference may be due to the fact that only a few records (68) were available to estimate the survival curves of patients with MS post diagnosis, introducing an inaccuracy in the determination of $\mathrm{p}[\mathrm{k}]$. However, such a declining total prevalence in NL may, in fact, be expected due to social factors. At the time of the previous study, the provincial population was increasing. However, the population has been steadily decreasing since 1984 (a yearly decline of $0.5 \%$ ). This is partially due to outmigration after the demise of cod fishery in 1993, historically the province's largest employer. The age of outmigrants is the working age group that cannot find employment on the island and closely matches the age at which MS is diagnosed (1555yrs). This age-biased outmigration will disproportionally affect the incidence of MS causing a decline in the overall prevalence - young Newfoundlanders and Labradoreans who move away will take their current or future diagnosis with them. Most of these are males. Therefore, because estimates from two different sources (case ascertainment via case searches and calculation based on current incidence and estimated survival) of the prevalence of MS in this province are not significantly different, we feel that our case ascertainment of diagnosed cases was near-complete.

This study has also shown an increase in the female to male ratio ( $\mathrm{F}: \mathrm{M}=2.69: 1$ - Table 1 ) compared to the previous study. This general increase in the female to male ratio over time has been observed by others ${ }^{34}$ and the current prevalence ratio is similar (2.69:1 in this study vs $2.6: 1$ in the US study), but this trend was also present in the previous incidence and prevalence study. The first 12 years of incidence in the previous study demonstrated a female to male ratio of 1.6:1, the final 12 years a female to male ratio of $2: 1$, and the final six years a female to male ratio of $3: 1$. Therefore, it is likely that this is a continuation of the trend shown in the previous study and in the United States and may either be due to a) a recent referral bias towards young women, b) a "catch up" to the true female to male ratio from a bias against referral of young women in the past, c) selective outmigration of males on economic grounds; or d) an actual trend in the natural history of this disease. Additional follow-up studies in other centers worldwide would guide researchers to corroborate our results and answer this question.

This updated study of the incidence and prevalence of MS in NL demonstrates an increased incidence and prevalence compared to previously reported rates. It is more likely that this has been due to better access to diagnostic equipment and diagnosticians than due to an increase in the actual incidence. The diagnosed incidence has recently stabilized and from this rate and an estimate of mortality, a prevalence that is slightly less than the current prevalence has been estimated. This may reflect the current population dynamics.

\section{ACKNOWLEDGEMENTS}

The authors thank Gwen Alcock, RN, of the NL MS Clinic, Don MacDonald from the Newfoundland and Labrador Center for Health Information, Dr Blair Fleming and Coleen Owens from the NLMedical Care Plan, Dr Sharon Buehler and Dr V Gadag of the Division of Community Health, MUN, and the NL neurologists, both current and previously-practicing.

\section{REFERENCES}

1. Paty DW, Ebers GC. Multiple Sclerosis. Contemporary Neurology Series. 1998; 50:48-138.

2. Noseworthy JH, Lucchinetti C, Rodriguez M, et al. Multiple sclerosis. N Engl J Med 2000; 343:938-952. 
3. Kurtzke JF. Epidemiologic contributions to multiple sclerosis: an overview. Neurology 1980; 30:61-79.

4. Weinshenker BG. Epidemiologic strategies to detect an exogenous cause of MS. Acta Neurol Scand (Suppl) 1995; 161:93-99.

5. Lauer K. Ecologic studies of multiple sclerosis. Neurology 1997; 49:S18-S26.

6. Olufemi SE, Green JS, Manickam P, et al. Common ancestral mutation in the MEN1 gene is likely responsible for the prolactinoma variant of MEN1 (MEN1Burin) in four kindreds from Newfoundland. Hum Mutat 1998; 11:264-269.

7. Xie YG, Zheng H, Leggo J, et al. A founder factor VIII mutation, valine 2016 to alanine, in a population with an extraordinarily high prevalence of mild hemophilia A. Thromb Haemost 2002; 87:178-179.

8. Spirio L, Green J, Robertson J, et al. The identical 5' splice-site acceptor mutation in five attenuated APC families from Newfoundland demonstrates a founder effect. Hum Genet 1999; 105:388-398.

9. Heutink P, Oostra BA. Gene finding in genetically isolated populations. Hum Mol Genet 2002; 11:2507-2515.

10. Pericak-Vance MA, Bebout JL, Gaskell PC, Jr., et al. Linkage studies in familial Alzheimer disease: evidence for chromosome 19 linkage. Am J Hum Genet 1991; 48:1034-1050.

11. Bertina RM, Koeleman BP, Koster T, et al. Mutation in blood coagulation factor $\mathrm{V}$ associated with resistance to activated protein C. Nature 1994; 369:64-67.

12. Rahman P, Jones A, Curtis J, et al. The Newfoundland population: a unique resource for genetic investigation of complex diseases. Hum Mol Genet 2003; 12 Spec No 2:R167-R172.

13. Mannion JJ. The Peopling of Newfoundland: Essays in Historic Geography. St John's: Memorial University of Newfoundland, 1977.

14. Statistics Canada 2001 Population Census 2001.

15. Bear JC, Nemec TF, Kennedy JC, et al. Inbreeding in outport Newfoundland. Am J Med Genet 1988; 29:649-660.

16. Bear JC, Nemec TF, Kennedy JC, et al. Persistent genetic isolation in outport Newfoundland. Am J Med Genet 1987; 27:807-830.

17. Martin LJ, Crawford MH, Koertvelyessy T, et al. The population structure of ten Newfoundland outports. Hum Biol 2000; 72:9971016.

18. Pryse-Phillips WE. The incidence and prevalence of multiple sclerosis in Newfoundland and Labrador, 1960-1984. Ann Neurol 1986; 20:323-328

19. Granieri E, Casetta I, Govoni V, et al. The increasing incidence and prevalence of MS in a Sardinian province. Neurology 2000; $55: 842-848$.

20. Granieri E, Casetta I, Tola MR. Epidemiology of multiple sclerosis in Italy and in southern Europe. Acta Neurol Scand (Suppl) 1995; 161:60-70.

21. Pugliatti M, Sotgiu S, Solinas G, et al. Multiple sclerosis epidemiology in Sardinia: evidence for a true increasing risk. Acta Neurol Scand 2001; 103:20-26.

22. Schumacher GA, Beebe G, Kibler RF, et al. Problems of experimental trials of therapy in multiple sclerosis: report by the panel on the evaluation of experimental trials of therapy in multiple sclerosis. Ann N Y Acad Sci 1965; 122:552-568.

23. Poser CM, Paty DW, Scheinberg L, et al. New diagnostic criteria for multiple sclerosis: guidelines for research protocols. Ann Neurol $1983 ; 13: 227-231$
24. McDonald WI, Compston A, Edan G, et al. Recommended diagnostic criteria for multiple sclerosis: guidelines from the international panel on the diagnosis of multiple sclerosis. Ann Neurol 2001; 50:121-127.

25. Lublin FD, Reingold SC. Defining the clinical course of multiple sclerosis: results of an international survey. National Multiple Sclerosis Society (USA) Advisory Committee on Clinical Trials of New Agents in Multiple Sclerosis. Neurology 1996; 46:907-911.

26. Kremenchutzky M, Cottrell D, Rice G, et al. The natural history of multiple sclerosis: a geographically based study. 7. Progressiverelapsing and relapsing-progressive multiple sclerosis: a reevaluation. Brain 1999; 122 ( Pt 10):1941-1950.

27. McDonnell GV, Hawkins SA. Primary progressive multiple sclerosis: a distinct syndrome? Mult Scler 1996; 2:137-141.

28. Freeman J, Hutchison GB. Prevalence, incidence and duration. Am J Epidemiol 1980; 112:707-723.

29. Esteve J, Benhamou E, Raymond L. Statistical methods in cancer research. Vol IV. Descriptive epidemiology. IARC Sci Publ 1994;1-302.

30. Mariotto $A B$, Verdecchia A. Using AIDS mortality data to reconstruct HIV/AIDS epidemics. Stat Med 2000; 19:161-174.

31. Verdecchia A, Capocaccia R, Egidi V, et al. A method for the estimation of chronic disease morbidity and trends from mortality data. Stat Med 1989; 8:201-216.

32. Verdecchia A, De Angelis G, Capocaccia R. Estimation and projections of cancer prevalence from cancer registry data. Stat Med 2002; 21:3511-3526.

33. Colonna M, Grosclaude P, Launoy G, et al. [Estimate of regional prevalence of colorectal cancer in France]. Rev Epidemiol Sante Publique 2002; 50:243-251.

34. Noonan CW, Kathman SJ, White MC. Prevalence estimates for MS in the United States and evidence of an increasing trend for women. Neurology 2002; 58:136-138.

35. Westlund KB, Kurland LT. Studies on multiple sclerosis in Winnepeg, Manitoba, and New Orleans, Louisiana. I. Prevalence; comparison between the patient groups in Winnipeg and New Orleans. Am J Hyg 1953; 57:380-396.

36. Stazio A, Kurland LT, Bell LG, et al. Multiple sclerosis in Winnipeg, Manitoba: methdological considerations of epidemiologic survey. Ten year follow-up of a community wide study, and population re-survey. J Chronic Dis 1964; 17:415-438.

37. Sweeney VP, Sadovnick AD, Brandejs V. Prevalence of multiple sclerosis in British Columbia. Can J Neurol Sci 1986; 13:47-51.

38. Hader WJ. Prevalence of multiple sclerosis in Saskatoon. Can Med Assoc J 1982; 127:295-297.

39. Hader WJ, Elliot M, Ebers GC. Epidemiology of multiple sclerosis in London and Middlesex County, Ontario, Canada. Neurology 1988; 38:617-621.

40. Klein GM, Rose MS, Seland TP. A prevalence study of multiple sclerosis in the Crowsnest Pass region of southern Alberta. Can $\mathbf{J}$ Neurol Sci 1994; 21:262-265.

41. Warren S, Warren KG. Prevalence of multiple sclerosis in Barrhead County, Alberta, Canada. Can J Neurol Sci 1992; 19:72-75.

42. Warren S, Warren KG. Prevalence, incidence, and characteristics of multiple sclerosis in Westlock County, Alberta, Canada. Neurology 1993; 43:1760-1763.

43. Svenson LW, Woodhead SE, Platt GH. Regional variations in the prevalence rates of multiple sclerosis in the province of Alberta, Canada. Neuroepidemiology 1994; 13:8-13. 